\title{
Article \\ Overexpression of OsABCG48 Lowers Cadmium in Rice (Oryza sativa L.)
}

\author{
Xingzhe Cai ${ }^{1,2}$, Meng Wang ${ }^{1}$, Yucong Jiang ${ }^{1,2}{ }^{\oplus}$, Changhu Wang ${ }^{1, *}$ and David W. Ow ${ }^{1, *}$ \\ 1 Plant Gene Engineering Center, Chinese Academy of Sciences, Key Laboratory of South China Agricultural \\ Plant Molecular Analysis and Genetic Improvement, Guangdong Key Laboratory of Applied Botany, \\ South China Botanical Garden, Chinese Academy of Sciences, Guangzhou 510650, China; \\ caixingzhe@scbg.ac.cn (X.C.); wangmeng@scbg.ac.cn (M.W.); jiangyc@scbg.ac.cn (Y.J.) \\ 2 University of Chinese Academy of Sciences, Beijing 100049, China \\ * Correspondence: cwang@scbg.ac.cn (C.W.); dow@berkeley.edu (D.W.O.); Tel.: +86-20-37087173 (C.W.)
}

Citation: Cai, X.; Wang, M.; Jiang, Y.; Wang, C.; Ow, D.W. Overexpression of OsABCG48 Lowers Cadmium in Rice (Oryza sativa L.). Agronomy 2021, 11, 918. https://doi.org/10.3390/ agronomy11050918

Academic Editor: Petr Smýkal

Received: 2 April 2021

Accepted: 4 May 2021

Published: 7 May 2021

Publisher's Note: MDPI stays neutral with regard to jurisdictional claims in published maps and institutional affiliations.

Copyright: (c) 2021 by the authors. Licensee MDPI, Basel, Switzerland. This article is an open access article distributed under the terms and conditions of the Creative Commons Attribution (CC BY) license (https:// creativecommons.org/licenses/by/ $4.0 /)$.

\begin{abstract}
Cadmium pollution threatens food safety and security by causing health issues and reducing farmland availability. Engineering genetic changes in crop plants to lower Cd accumulation can be a cost-effective approach to address this problem. Previously, we reported that a rice line, $2 \mathrm{~B}$, which expresses a truncated version of $\mathrm{OsO} 3 \mathrm{~L} 2 \mathrm{had}$ reduced $\mathrm{Cd}$ accumulation throughout the plant, including in seed. However, downstream events caused by expression of this gene were not known. In this study, RNA-seq was used to identify differentially expressed genes between the wild type and $2 \mathrm{~B}$ rice with or without $\mathrm{Cd}$ treatment, leading to the study of an $A B C$ transporter gene, OsABCG48 (ATP-Binding Cassette transporter G family member 48). Heterologous expression of OsABCG48 conferred tolerance to Cd in Schizosaccharomyces pombe, Arabidopsis and rice. Moreover, overexpressing OsABCG48 in rice lowered root $\mathrm{Cd}$ accumulation that was associated with more extensive lateral root development. These data suggest that OsABCG48 might have applications for engineering low-Cd rice.
\end{abstract}

Keywords: ABC transporter; Cd stress; RNA-seq; expression profiling; rice (Oryza sativa)

\section{Introduction}

Cadmium $(\mathrm{Cd})$ is one of the most concerning environmental pollutants in the world. As a nonessential metal, it replaces essential metals to cause ion homeostasis disruption, protein dysfunction, DNA and plasma membrane damage and reactive oxygen species accumulation [1-5]. Cd can lead to brittle bones and has a long biological half-life ( 10-30 years) in the kidney, such that even low-dose intake from chronic exposure can cause kidney failure [6]. A major route of $\mathrm{Cd}$ intake is through the food chain; although farm animal bones and internal organs are not a major part of the human diet, especially in developed countries, plant-derived $\mathrm{Cd}$ is a major source [7,8]. Cd from contaminated soil can be transferred to humans via plant uptake, and $\mathrm{Cd}$ soil pollution has been a concern for food security and public health. Cd dietary intake is mainly from leafy vegetables and especially cereals, since the latter are consumed at greater quantities. $\mathrm{Cd}$ contamination in rice and durum wheat has been reported on many occasions, and in the case of rice, it has been a publicized problem in many parts of East and South East Asia, especially since rice provides the major calorie intake [9-14].

Although the remediation of soil could solve the problem at its source, neither soil cleaning nor replacement has been an affordable option. Soil replacement over the course of 30 years in Japan's Toyama Prefecture, the site where Cd pollution caused the "Itai-itai disease" in the 1940s [14], costed JPY 40.7 billion for 863 hectares, or JPY 47 million ( USD $438,000)$ per hectare [15]. Compared with soil remediation, a more cost-effective means to address the issue of $\mathrm{Cd}$ dietary intake is to develop crop plants that can reduce $\mathrm{Cd}$ 
accumulation in edible parts. Toward this goal, the engineering of lower $\mathrm{Cd}$ accumulation in rice has been reported by several groups.

Several genes that have been engineered to lower $\mathrm{Cd}$ accumulation encode ion transporters. A manganese (Mn) transporter, OsNramp5, has been shown to affect $\mathrm{Cd}$ accumulation in root, straw and grain [16]. However, unless the soil has sufficient Mn, reducing the production of OsNramp5 also causes Mn deficiency. With certain down-regulated alleles of OsNramp5, Cd uptake in rice decreased without affecting grain yield, although the grain Mn nutrient was reduced to a third of its normal level [17]. The P1B-type ATPase transporter OsHMA3 was found to affect $\mathrm{Cd}$ translocation from roots to above ground tissues [18]. Overexpression of OsHMA3 reduced $\mathrm{Cd}$ in dehusked (brown) rice through sequestration of Cd into root vacuoles. The OsLCT1 (Low-affinity Cation Transporter 1) transporter moves $\mathrm{Cd}$ from the xylem through phloem to grain, and plants with lower production of OsLCT1 showed reduced grain Cd accumulation of $\sim 50 \%$ but had increased grain $\mathrm{Fe}$ by $\sim 33 \%$ [19].

There are also non-transporter genes involved in $\mathrm{Cd}$ accumulation in rice. Plants that fail to express $L C D$ (Low CaDmium) showed about a $55 \%$ reduction in grain $\mathrm{Cd}$ when grown in soil with low Cd contamination [20]. More recently, this laboratory reported engineering the production of full-length or truncated versions of OsO3L2 and OsO3L3 that lowered grain Cd [21,22]. These proteins are members of the OXS3 (OXidative Stress 3) family, where in Arabidopsis thaliana, OXS3 is needed for tolerance to metal and oxidative stress [23] and plays a role in regulating stress-induced flowering time [24].

In this study, we describe an RNA-seq analysis on the rice line 2B, which overproduces a truncated form of $\mathrm{OsO} 3 \mathrm{~L} 2$ that has been shown previously to reduce $\mathrm{Cd}$ accumulation in rice [21]. After comparing line $2 \mathrm{~B}$ to the wild type (WT) without or with $\mathrm{Cd}$, we focused our study on $O s A B C G 48$, a gene involved in Cd tolerance and accumulation in rice that belongs to the $\mathrm{ABC}$ transporter $\mathrm{G}$ family.

\section{Materials and Methods}

\subsection{Plant Culture and Treatment}

Seeds from rice (Oryza sativa japonica L.) cultivar Zhonghua11 and its derivative line 2B were surface sterilized with $5 \%$ sodium hypochlorite, washed with distilled water 3 times and germinated for 2 days in the dark at $30^{\circ} \mathrm{C}$. After germination, seedlings were transferred to polyethylene containers with $1 / 2$ Kimura $\mathrm{B}$ nutrient solution ( $\mathrm{pH}$ 5.6). The Kimura $\mathrm{B}$ nutrition solution contained $\left(\mathrm{NH}_{4}\right)_{2} \mathrm{SO}_{4}, \mathrm{MgSO}_{4} \cdot 7 \mathrm{H}_{2} \mathrm{O}, \mathrm{KNO}_{3}, \mathrm{Ca}\left(\mathrm{NO}_{3}\right)_{2} \cdot 4 \mathrm{H}_{2} \mathrm{O}$ and $\mathrm{KH}_{2} \mathrm{PO}_{4}$ and micronutrients $\mathrm{MnCl}_{2} \cdot 4 \mathrm{H}_{2} \mathrm{O}, \mathrm{H}_{3} \mathrm{BO}_{3},\left(\mathrm{NH}_{4}\right)_{6} \mathrm{Mo}_{7} \mathrm{O}_{24} \cdot 4 \mathrm{H}_{2} \mathrm{O}, \mathrm{ZnSO}_{4} \cdot 7 \mathrm{H}_{2} \mathrm{O}$, $\mathrm{CuSO}_{4} \cdot 5 \mathrm{H}_{2} \mathrm{O}$ and Fe-EDTA (All regents purchased from Sigma-Aldrich, St. Luis, MO, USA). After incubation for 2 days in the dark at $30^{\circ} \mathrm{C}$, and 12 days under long-day conditions ( $16 \mathrm{~h}$ light $/ 8 \mathrm{~h}$ dark) at $28^{\circ} \mathrm{C}$, the 14-day-old seedlings were transferred to new nutrient solution for $12 \mathrm{~h}$ without or with $75 \mu \mathrm{M} \mathrm{Cd}$. Afterwards, whole seedlings were washed 3 times to remove surface $\mathrm{Cd}$ and frozen in liquid nitrogen for RNA extraction. Each rice line with or without $\mathrm{Cd}$ treatment was sampled in duplicate, giving rise to 8 samples for RNA-seq analysis.

For Cd tolerance assay in rice, 2-day-old seedlings of the wild type and three Os$A B C G 48$ overexpression lines were cultured in $1 / 2$ Kimura B nutrient solution ( $\mathrm{pH} 5.6$ ) containing 0 or $2 \mu \mathrm{M} \mathrm{Cd}$ for 5 days. The root and shoot lengths of each seedling were measured and photographed with 3 biological replicates. For the $\mathrm{Cd}$ uptake experiments, rice seedlings were cultured with nutrient solution for 28 days and then treated with $2 \mu \mathrm{M}$ $\mathrm{Cd}$ for $12 \mathrm{~h}$, refreshed with new solution every week. Roots and shoots of seedlings were sampled and dried at $80^{\circ} \mathrm{C}$ in an oven to constant dry weight, followed by digestion with $\mathrm{HNO}_{3}$ in the Microwave Sample Preparation System (Multiwave3000, Anot Paar, Austria). The Cd concentration was determined by ICP-MS (Agilent 7700X, Agilent Technologies, Santa Clara, CA, USA). 


\subsection{RNA-seq Library Construction, Sequencing and Data Analysis}

WT and line 2B seedlings were grown on $1 / 2$ Kimura B nutrient solution (pH 5.6) for 14 days and then treated with 0 or $75 \mu \mathrm{M} \mathrm{CdCl}_{2}$ for $12 \mathrm{~h}$. Whole seedlings were collected and sent for sequencing by Illumina HiSeq ${ }^{\mathrm{TM}}$ PE150 (Illumina, San Diego, CA, USA) and an index of the reference genome (MSU Rice Genome Annotation Project Release 7.0) was built using Bowtie (v2.2.3), and paired-end clean reads were aligned to the reference genome using TopHat (v2.0.12) by Novogene (Beijing, China), where total RNA isolation, library construction, sequencing, assessment of RNA-seq quality, screening of DEGs (Differentially Expressed Genes) and their expression analysis (heat map) were conducted. Sequencing was set to obtain 6-10 G clean bases for each sample. FPKM (fragments per kilobase of transcript sequence per million base pairs sequenced) was used to calculate the expression level for transcripts [25]. Identification of DEGs was conducted by the DESeq R package (v1.18.0) in the R (v3.5.1) environment with adjusted $p$-values $<0.05$, whereas probability $p_{\text {dj }}$ values were adjusted using Benjamin and Hochberg's approach for controlling the false discovery rate [26]. Heat maps were created with the pheatmap R package (v1.0.10), using the $\lg ($ FPKM + 1) values for clustering. RNA-seq data were deposited in the NCBI Sequence Read Archive database under the accession numbers SAMN16930351 to SAMN16930358. Portions of the RNAs used for RNA-seq were kept for subsequent qRT-PCR (quantitative Reverse Transcription Polymerase Chain Reaction) verification.

\section{3. $q R T-P C R$}

Total RNA was isolated by TRIzol reagent (Invitrogen, Carlsbad, CA, USA) for qRTPCR analysis. cDNA synthesis was carried out with total RNA using a PrimeScript ${ }^{\mathrm{TM}}$ RT reagent kit with a gDNA Eraser (Takara, China). SYBR Premix Ex Taq (Tli RNaseH Plus) (Takara, China) was used for qRT-PCR on a LightCycler ${ }^{\circledR} 480$ II/96 qPCR System (Roche, Rotkreuz, Switzerland) following a reaction protocol of $95^{\circ} \mathrm{C}$ for $30 \mathrm{~s}, 40$ cycles of $95^{\circ} \mathrm{C}$ for $5 \mathrm{~s}$ and $60{ }^{\circ} \mathrm{C}$ for $31 \mathrm{~s}$. OsActin-1 and AtUBQ5 were used as reference genes for rice and Arabidopsis, respectively. Primers listed in Table S1 were designed using Sigma-Aldrich qRT-PCR primer tools (St. Luis, MO, USA). The 14-day-old rice and 21-day-old Arabidopsis plants were grown as described in Sections 2.1 and 2.5, respectively.

\subsection{Cd Tolerance Assay in S. Pombe}

Full-length cDNAs of selected DEGs were from qRT-PCR and cloned into pART1 by in-Fusion HD cloning (Clontech, Shiga, Japan). After verification by DNA sequencing, expression constructs were transformed into S. pombe strain JS23 $\left(h^{+}\right.$, ura4.294, leu1.32) by the LiAc method $[27,28]$. For assessing Cd tolerance, S. pombe cells in 10-fold serial dilutions were spotted onto EMM (Edinburgh Minimal Medium) + uracil media agar plates containing different concentrations of $\mathrm{CdCl}_{2}$ (Sigma) and incubated at $30{ }^{\circ} \mathrm{C}$ for 5 to 7 days.

\subsection{Expression of OsABCG48 in Plants}

Coding sequences of OsABCG48 and OsHIPP43 were inserted separately into pSUPER1300 by in-Fusion HD cloning (Clontech) and introduced into Agrobacterium tumefaciens GV3101 for transformation into Arabidopsis ecotype Columbia-0 (Col-0) by the floral dip method [29]. Putative T1 transformants were screened in $1 / 2 \mathrm{MS}$ plates containing $50 \mathrm{mg}$ $\mathrm{mL}^{-1}$ of hygromycin. T1 plants were transplanted on soil for harvesting T2 seeds for PCR confirmation of the OsABCG48 transformation. T3 individuals from T2 self-fertilization were used to deduce T2 homologous lines based on Mendelian segregation. The T-DNA insertion mutant of AtABCG34 (SALK_082843) was obtained from the Arabidopsis Biological Resource Center. The Arabidopsis root growth assay and transgene expression analysis were performed on vertically placed plates containing $1 / 2$ strength MS with or without $\mathrm{CdCl}_{2}(0,25,50,75$ and $100 \mu \mathrm{M}), \mathrm{MnSO}_{4}(0,25,50,75,100$ and $125 \mu \mathrm{M})$ or $\mathrm{CuSO}_{4}(0,12.5$, $25,37.5,50 \mu \mathrm{M})$ for 21 days.

For rice transformation, the Agrobacterium-mediated method was used [30], and regenerated plants were selected on $1 / 2 \mathrm{MS}$ medium containing $100 \mathrm{mg} \mathrm{L}^{-1}$ of hygromycin. For 
the OsABCG48 overexpression analysis, seedlings were grown in $1 / 2$ Kimura B nutrient solution ( $\mathrm{pH}$ 5.6) containing 0 or $2 \mu \mathrm{M} \mathrm{Cd}$ for 5 days, as for the $\mathrm{Cd}$ tolerance assay.

\section{Results}

\subsection{RNA-Seq Analysis and Identification of Differentially Expressed Genes}

Previously, we described that the rice line $2 \mathrm{~B}$ that expresses the truncated form of OsO3L2 was able to reduce the overall Cd content in rice [21]. As OsO3L2 is an OXS3 (OXidative Stress 3) protein family member that resides in the nucleus and co-localizes with histone $\mathrm{H} 2 \mathrm{~A}[21,23]$, we speculated that OsO3L2 might be a regulator of downstream genes. To determine the genes that were associated with $\mathrm{Cd}$ tolerance and low $\mathrm{Cd}$ accumulation in the 2B genotype, we conducted a genome-wide analysis of transcripts using highthroughput RNA-seq. Eight libraries were constructed, with two replicates of the following four sample types: (1) wild type without $\mathrm{Cd}(\mathrm{WT}-\mathrm{Cd}),(2)$ wild type with $\mathrm{Cd}(\mathrm{WT}+\mathrm{Cd})$, (3) line $2 \mathrm{~B}$ without $\mathrm{Cd}(2 \mathrm{~B}-\mathrm{Cd})$ and $(4)$ line $2 \mathrm{~B}$ with $\mathrm{Cd}(2 \mathrm{~B}+\mathrm{Cd})$.

RNA-seq revealed a total number of 1420 DEGs using $P_{\text {adj }}<0.05$ as a cutoff on $42,211,728-61,852,692$ clean reads. As depicted in the heat map in Figure 1A, the DEGs were grouped into six clusters (cluster I to VI) based on the similarity of their gene expression profiles. The comparison between the WT and $2 \mathrm{~B}$ columns shows that regardless of $\mathrm{Cd}$ treatment, 2B plants showed down-regulated DEGs in clusters I and III, but upregulated DEGs in clusters V and VI. Since these four clusters comprise $~ 65 \%$ of the total DEGs, the $2 \mathrm{~B}$ genotype itself contributed a major change in gene expression. As for changes caused by Cd, both WT and 2B plants showed Cd-upregulated genes ( $45 \%$ of the total DEGs) in clusters II and V, and Cd-down-regulated genes in clusters III and IV ( $23 \%$ of the total DEGs), but the DEG changes in clusters III and V ( $33 \%$ of the total DEGs) were the combined effects of both the $2 \mathrm{~B}$ genotype and $\mathrm{Cd}$ treatment.

The comparisons among the four treatment groups are shown in the Venn diagram in Figure 1B. Cd caused 5.4-fold more DEGs (729, blue) (Table S2) in WT than in 2B plants (135, green) (Table S3). Comparing between 2B and WT, only 275 DEGs (purple) were found in the absence of Cd (Table S4), but 616 DEGs (yellow) were found when treated with Cd (Table S5). Of particular interest was the 561 DEGs unique to the WT $-\mathrm{Cd}$ vs. WT $+\mathrm{Cd}$ comparison as well as the $50 \mathrm{DEGs}$ unique to the $2 \mathrm{~B}-\mathrm{Cd}$ vs. $2 \mathrm{~B}+\mathrm{Cd}$ comparison. The 10-fold higher DEGs in WT plants (561 vs. 50) could possibly indicate that more DEGs were needed to mitigate the damage caused by the higher accumulation of $\mathrm{Cd}$, as though $2 \mathrm{~B}$ plants might have already been primed to better tolerate $\mathrm{Cd}$ stress. Based on this hypothesis, those genes primed to better tolerate $\mathrm{Cd}$ stress in $2 \mathrm{~B}$ plants would be among the 275 DEGs between WT and 2B in the absence of Cd (Figure 1C). Since 150 of those genes were common between $W T+C d$ and $2 B+C d$, this leaves $125 D E G s$ unique to the $2 B$ genotype prior to $\mathrm{Cd}$ treatment. $\mathrm{Cd}$ treatment in 2B plants caused $135 \mathrm{DEGs}$ (Figure 1D), but 73 of them were common in the Cd treatment of WT; therefore, only 62 were unique to the 2B genotype. These comparisons suggest that 187 DEGs (125 prior to Cd stress; 62 after $\mathrm{Cd}$ stress) could be the focus in finding the genes responsible for the $2 \mathrm{~B}$ low-Cd phenotype.

\subsection{Verification of DEGs Possibly Related to Ion Transportation}

Since numerous studies have identified transporter genes to be involved in $\mathrm{Cd}$ accumulation, including OsNramp5, OsHMA3, OsLCT1, OsLCD, CAL1 and OsCd1 [16-20,31,32], we were particularly entertained by the possibility that the low $\mathrm{Cd}$ accumulation in $2 \mathrm{~B}$ plants might be due to DEGs in metal ion transport. Based on this consideration, eight DEGs potentially involved in substrate transport were selected, including WAT1 (Walls Are Thin 1)-related genes OS10G0199500 and OS04G0422300, $A B C G$ ( $A B C$ transporter $G$ family) genes OS11G0587600 (OsABCG48) and OS07G0522500 (OsABCG43), probable aquaporin genes OS01G0975900 (OsTIP1) and OS09G0541000 (OsPIP2-7), a HIPP (Heavy metal-associated Isoprenylated Plant Protein) gene OS04G0661100 (OsHIPP43) and an nsLTP(non-specific Lipid-Transfer Protein) gene OS03G0793900 (OsnsLTP2) (Figure 2A). According to Gene Ontology (http:/ / www.geneontology.org), WAT1 and ABCG genes 
encode drug/metabolite transporters. The aquaporin genes also have probable transporter activities, OsHIPP43 encodes a heavy metal-associated domain that might function in metal ion transport and OsnsLTP2 has been speculated to have ion transmembrane transporter activity. To verify the RNA-seq results (Figure 2A), qRT-PCR was conducted on these eight genes (Figure 2B-I). However, the qRT-PCR data could not confirm that expression of OS10G0199500 (WAT1-related gene) was higher in 2B than in WT without Cd treatment (Figure 2A,B), and they failed to detect differential expression of OS07G0522500 (OsABCG43) between WT and 2B under Cd stress (Figure 2A,E). For OS04G0422300, a statistically significant difference was found only between $2 \mathrm{~B}-\mathrm{Cd}$ and $\mathrm{WT}+\mathrm{Cd}$ (Figure 2C). Aside from these three, the expressions of the other five genes were confirmed by qRT-PCR and were advanced for further analysis.

A

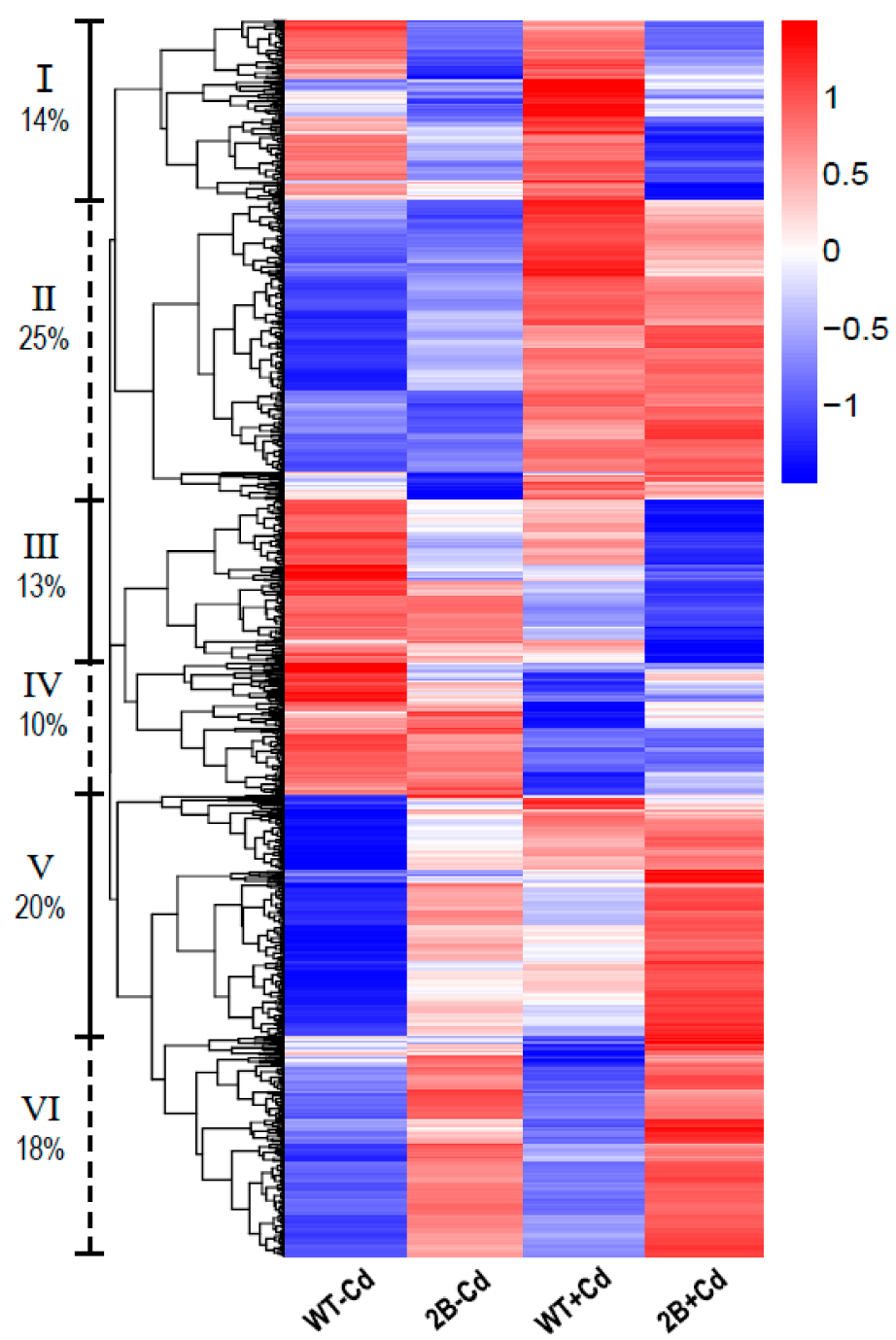

B

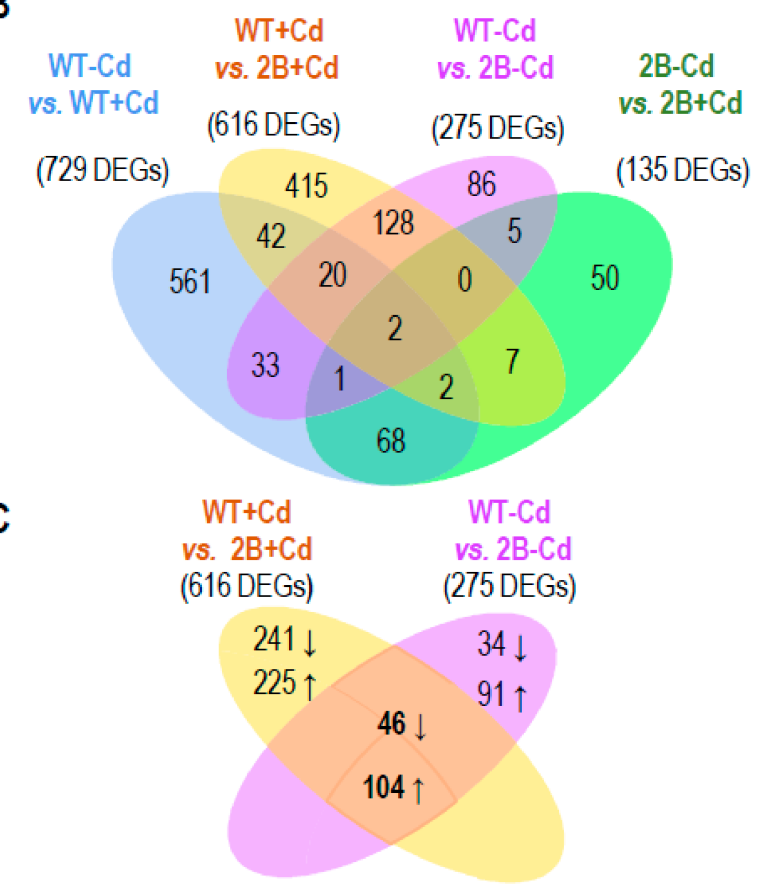

D

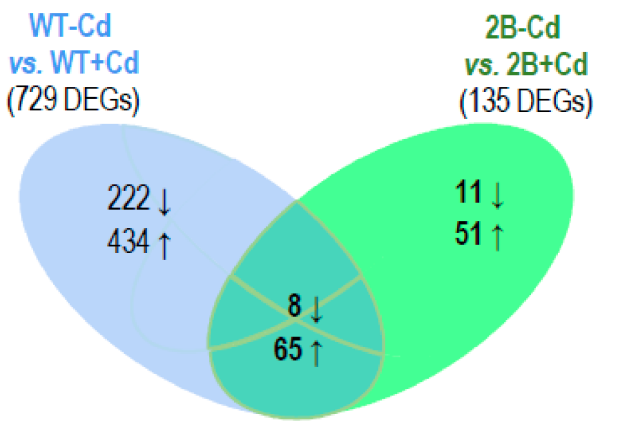

Figure 1. Expression profiling on rice altered by 2B expression and/or Cd treatment. (A) Heat map shows a one-dimensional hierarchical cluster analysis of 1420 DEGs (differentially expressed genes). Clusters I to VI produced according to the lg $($ FPKM +1$)$ values, $\%$ of total shown. (B) Venn diagram shows four comparison groups. (C) Comparison of WT + Cd vs. $2 \mathrm{~B}+\mathrm{Cd}$ and $\mathrm{WT}-\mathrm{Cd}$ vs. $2 \mathrm{~B}-\mathrm{Cd}$. (D) Comparison of $\mathrm{WT}-\mathrm{Cd}$ vs. $\mathrm{WT}+\mathrm{Cd}$ and $2 \mathrm{~B}-\mathrm{Cd}$ vs. $2 \mathrm{~B}+\mathrm{Cd}$. Number of genes in each partition with up or down arrows indicates up- or down-regulation, respectively. 


\begin{tabular}{|c|c|c|c|}
\hline Gene ID & Gene description (gene name) & WT-Cd & $2 B-C d|W T+C d| 2 B+C d$ \\
\hline OS10G0199500 & WAT1-related protein & & \\
\hline OS04G0422300 & WAT1-related protein & & \\
\hline OS11G0587600 & ABC transporter G family member 48-like (OsABCG48) & & \\
\hline OS07G0522500 & ABC transporter G family member 43-like (OsABCG43) & & \\
\hline OS01G0975900 & probable aquaporin TIP1-2 (OsTIP1) & & \\
\hline OS09G0541000 & probable aquaporin PIP2-7 (OsPIP2-7) & & \\
\hline OS04G0661100 & $\begin{array}{l}\text { heavy metal-associated isoprenylated plant protein } 43 \\
\text { (OsHIPP43) }\end{array}$ & & \\
\hline OS03G0793900 & non-specific lipid-transfer protein 2 (OsnsLTP2) & & \\
\hline
\end{tabular}
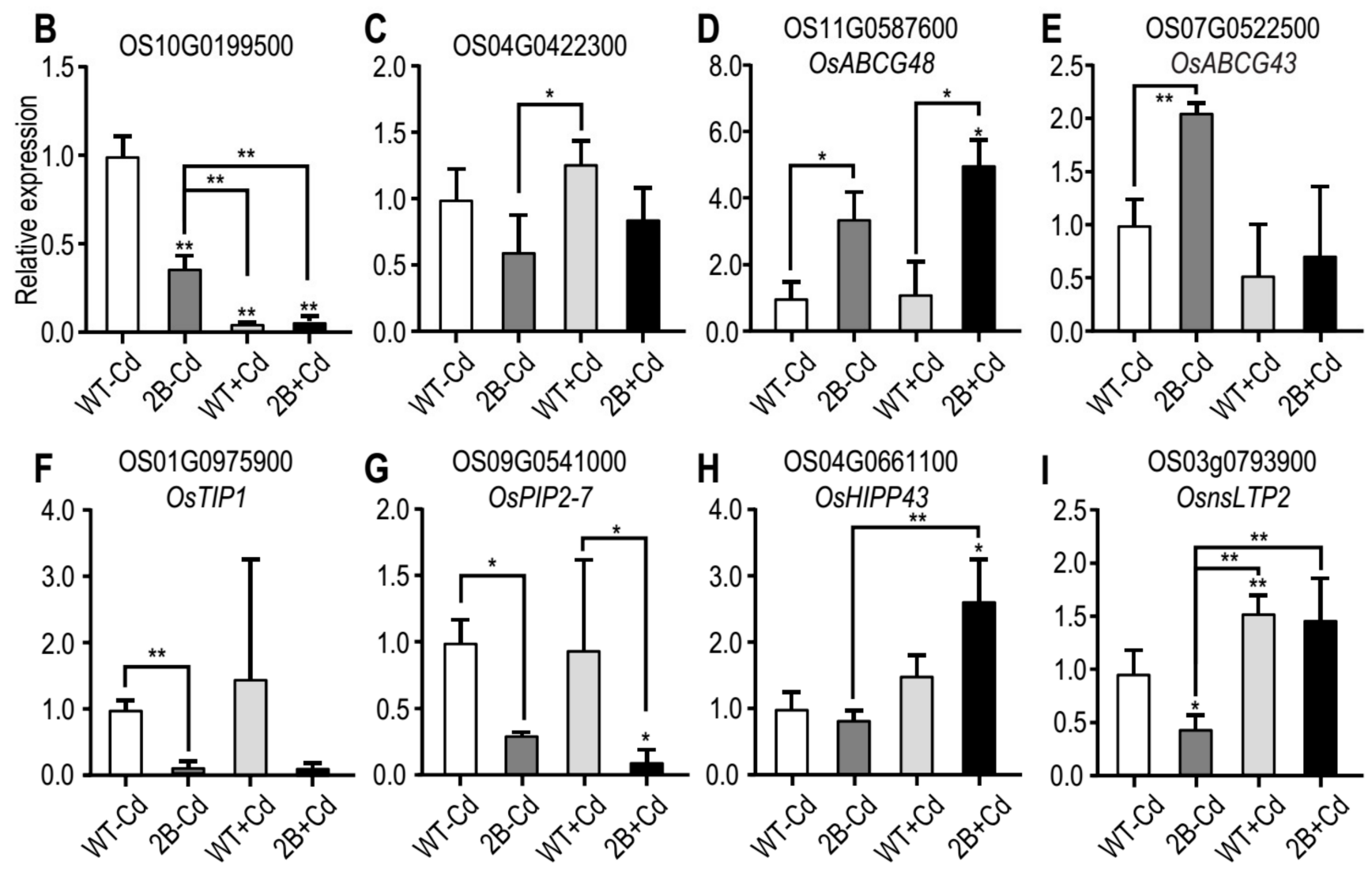

Figure 2. RNA-seq and qRT-PCR comparisons of candidate transporter genes. (A) DEGs with transporter-associated activity identified by RNA-seq. Green to red color scale indicates down- to upregulation. (B-I) qRT-PCR of gene expression normalized to OsActin-1. Data (bar and error bar) are shown as mean $\pm \operatorname{SD}(n=3)$. Unpaired Student's $t$-test used for statistical significance $\left.{ }^{*} p<0.05,{ }^{* *} p<0.01\right)$ of samples indicated on top of connecting lines, or by comparison to WT $-\mathrm{Cd}$ indicated on top of error bar.

\subsection{Heterologous Expression of OsABCG48 Conferred Tolerance to Cd in S. pombe and Arabidopsis}

Since the production of the OsO3L2 protein and its truncated 2B peptide is known to enhance oxidative stress tolerance in S. pombe [21], we cloned these five genes into vector pART1 and transformed it into fission yeast. Enhanced Cd tolerance was observed only for OS04G0661100 (OsHIPP43) and OS11G0587600 (OsABCG48) (Figure 3A). We next tested whether OsHIPP43 and OsABCG48 could enhance Cd tolerance in Arabidopsis. Each gene 
was expressed from the strong mannopine synthase-derived promoter Super $_{\text {pro, }}$, and after Agrobacterium-mediated transformation, six OsHIPP43- and nine OsABCG48-expressing lines were obtained. Two randomly chosen lines of each were tested on a range of $\mathrm{CdCl}_{2}$ concentrations $(0 \mu \mathrm{M}, 25 \mu \mathrm{M}, 50 \mu \mathrm{M}, 75 \mu \mathrm{M}$ and $100 \mu \mathrm{M})$. Although T3 homozygous seedlings of two OsHIPP43-transformed lines showed OsHIPP43 expression (Figure S1A), they did not show enhanced tolerance to $\mathrm{Cd}$. For the two OsABCG48 expression lines, OsABCG48-a and OsABCG48-b, they grew about $22 \%$ to $23 \%$ longer roots than the WT control in $50 \mu \mathrm{M}$ of $\mathrm{Cd}$, but statistically significant differences were not observed with lower or higher Cd concentrations (Figure 3B,C). We also tested a knockout line (SALK_082843) of AtABCG34, the most closely related OsABCG48 ortholog in Arabidopsis (Figure S2). The two OsABCG48 expression lines grew $44 \%$ to $45 \%$ longer roots than the Atabcg 34 knockout line (Figure 3B,C). qRT-PCR verified that this mutant lacked AtABCG34 expression, while detectable OsABCG48 transcription was found in the OsABCG48 expression lines (Figure S1B-D). Since the manganese transporter Nramp5 in rice can mediate Cd transport [16], and HIPPs can lower the kinetic barrier for $\mathrm{Cu}$ transfer [33,34], we also tested $\mathrm{Mn}$ and $\mathrm{Cu}$ tolerance. However, no significant difference was found between the WT and the OsABCG48-expressing line (Figure S3). This indicates that OsABCG48 specifically confers tolerance to $\mathrm{Cd}$ and not to $\mathrm{Cu}$ or $\mathrm{Mn}$.

A

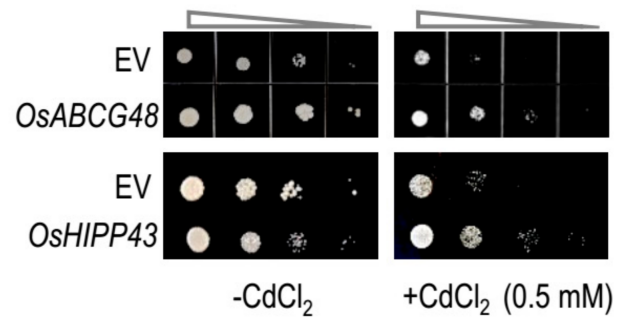

C

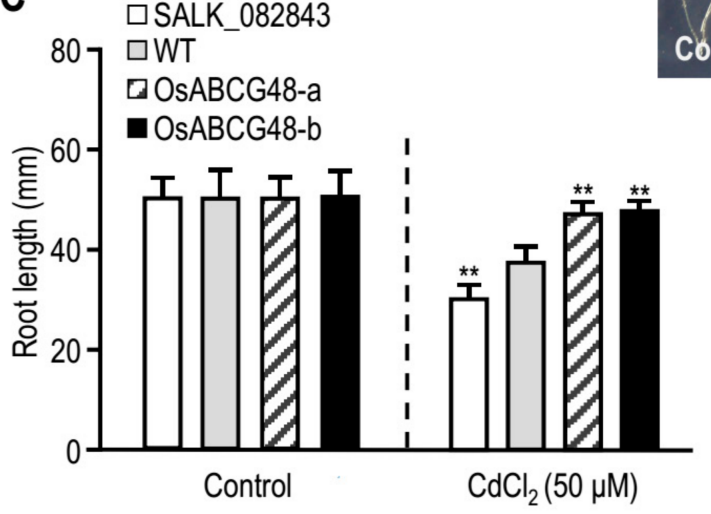

B

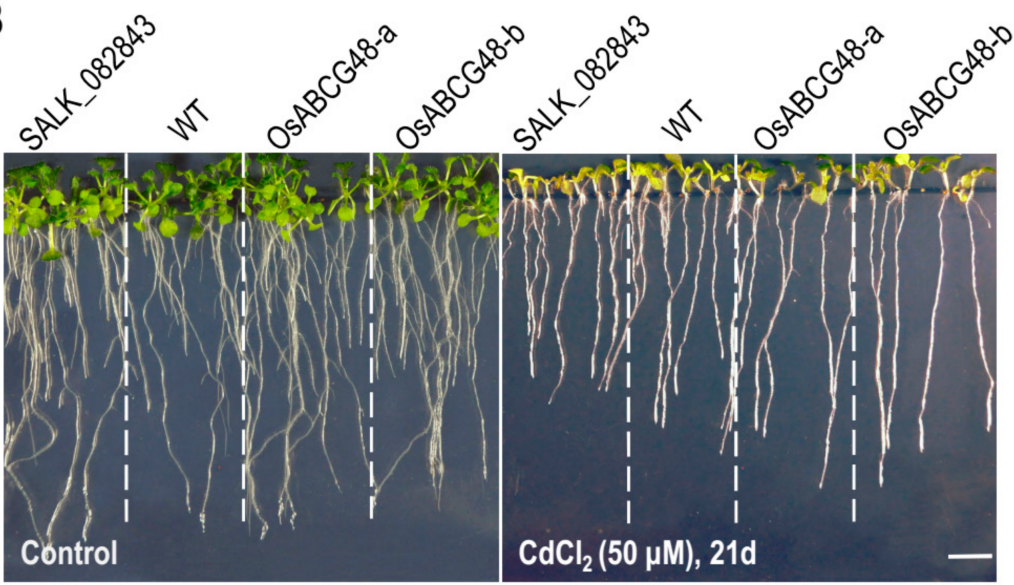

Figure 3. Expression of OsABCG48 confers tolerance to Cd in S. pombe and Arabidopsis. (A) Dilution (10-fold) bioassay of S. pombe strains on $\mathrm{EMM}+$ uracil agar plates without or with $\mathrm{CdCl}_{2}(0.5 \mathrm{mM}) ; \mathrm{EV}$ is empty vector control. (B) Cd tolerance assay of OsABCG48 expression lines of Arabidopsis. (C) Root length recorded from 21-day-old seedlings germinated and grown in medium without or with $50 \mu \mathrm{M} \mathrm{CdCl}_{2}$. Figure $3 \mathrm{~B}$ is from a representative experiment among three with similar results. Atabcg34 T-DNA knockout line (SALK_082843) used as negative control. Data (bar and error bar) are shown as mean $\pm \mathrm{SD}(n=13$ to 19$)$; statistical analysis by unpaired Student's $t$-test compared to WT $\left.{ }^{* *} p<0.01\right)$; scale bar $=1 \mathrm{~cm}$.

\subsection{Overexpressing OsABCG48 Enhances Cd Tolerance and Lowers Cd Accumulation in Rice}

To explore a possible relationship between the tissue-specific expression and function of OsABCG48, paddy-grown rice was sampled after two weeks of flowering. The qRTPCR assay showed that OsABCG48 was expressed in the nodes, stems and seeds and 
more so in the roots and leaves (Figure 4A). Along with the data from RiceXPro (http: // ricexpro.dna.affrc.go.jp accessed on 30 September 2020) that OsABCG48 showed the highest expression in the roots (Figure S4), it seems most probable that OsABCG48 has the highest activity in the roots.
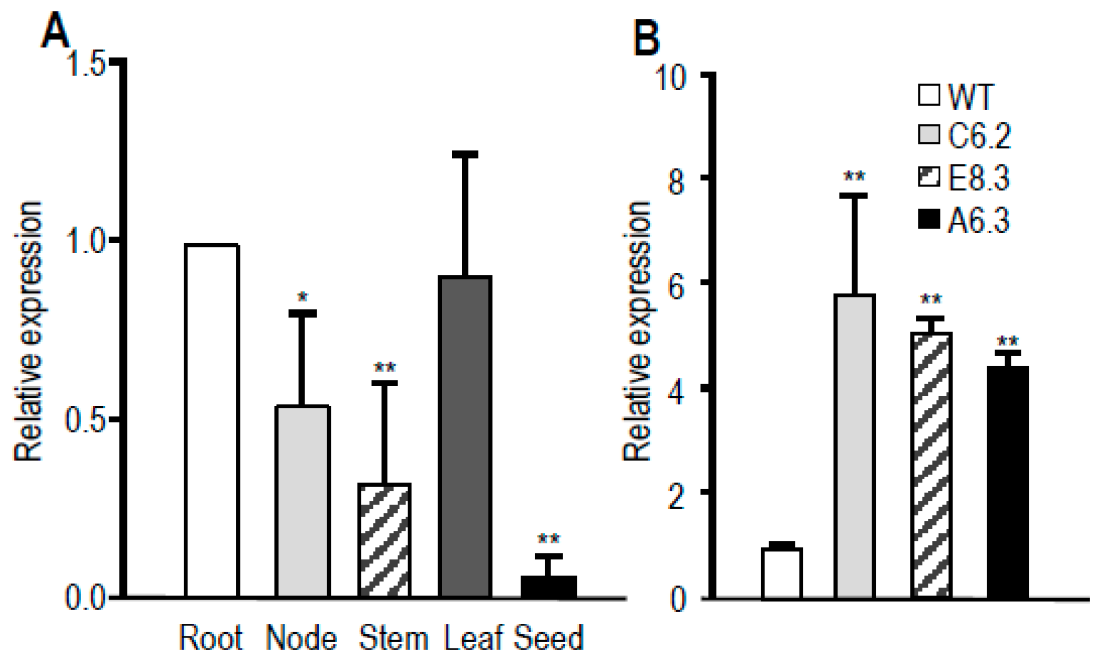

Figure 4. Expression of $O s A B C G 48$ in rice normalized to OsActin-1. (A) Field-grown WT rice two weeks after flowering. (B) Seven-day-old T2 seedlings from OsABCG48-transformed lines C6.2, E8.3 and A6.3. Data (bar and error bar) are shown as mean $\pm \operatorname{SD}(n=3)$; statistical analysis by unpaired Student's $t$-test compared to WT $\left(^{*} p<0.05,{ }^{* *} p<0.01\right)$.

Using the same Arabidopsis expression constructs, we conducted Agrobacterium-mediated transformation on eight embryogenetic rice calluses (Table S6). Multiple T0 plants were regenerated from each callus. Of the $\mathrm{T} 0$ plants derived from the six calluses that produced seeds, 7 out of 16 T0 plants (A5, C4, C8, F2, F7, G1 and G6) were likely to be singlelocus based on resistance to sensitive segregation data from germination on hygromycincontaining plates. In the sampling of 88 out of 359 hygromycin-resistant clones, $74 \%$

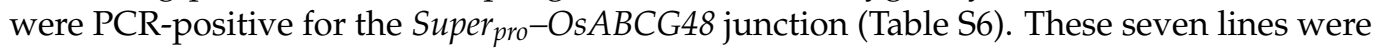
preserved to produce homozygous T3 and T4 seeds for testing of grain Cd. However, for the other T0 plants deemed to harbor multiple OsABCG48 loci, we could afford to use them to test the effect from overexpression of OsABCG48. T2 seedlings from three multi-loci lines (A6.3, C6.2 and E8.3) were found to show 5-fold higher expression of OsABCG48 than WT plants (Figure $4 \mathrm{~B}$ ). While these T2 seedlings did not show a difference in primary root and shoot lengths in the absence of $\mathrm{Cd}$, the presence of $\mathrm{Cd}$ reduced primary root and shoot lengths by about half in both WT and OsABCG48 overexpression lines, but the primary root lengths of three overexpressing lines were $12 \%$ to $17 \%$ longer than WT after a 5-day treatment with $2 \mu \mathrm{M} \mathrm{CdCl}_{2}$ (Figure $5 \mathrm{~A}-\mathrm{D}$ ). Aside from the primary root length, differences were also found on lateral roots, especially on those developed from the primary root as each of the three overexpressing lines grew three- to four-fold more and longer lateral roots than the WT when treated with Cd (Figure $5 \mathrm{~B}, \mathrm{E}$ ). It is possible that more and longer lateral roots in the OsABCG48 overexpression plants had compensated for the Cd-repressed growth of primary roots and hence contributed to $\mathrm{Cd}$ tolerance.

Most importantly, we want to know whether overexpression of OsABCG48 could lower $\mathrm{Cd}$ accumulation, like the overexpression of OsO3L2 or its truncated fragment $2 B$ [21,22]. T2 seedlings of lines A6.3, C6.2 and E8.3 were geminated and cultured hydroponically for 28 days before transplanting into the same solution containing $2 \mu \mathrm{M} \mathrm{Cd}$ for another $12 \mathrm{~h}$. Roots and shoots were then harvested, dried and subjected to ICP-MS analysis. The results showed that the root $\mathrm{Cd}$ of these T2 seedlings varied from 46.9 to $70.9 \mathrm{mg} / \mathrm{kg}$, or $39 \%$ to $60 \%$ less root $\mathrm{Cd}$ than the $116 \mathrm{mg} / \mathrm{kg}$ in the WT control (Figure 5F). Although a lower Cd content was not observed in shoots, the values were under $0.2 \mathrm{mg} / \mathrm{kg}$, suggesting that the $12-\mathrm{h}$ 
treatment might not have been long enough for $\mathrm{Cd}$ to reach above ground tissues. Since OsNramp5, OsHMA3, OsLCT1 and OsO3L2 were reported to affect Cd accumulation, we measured their expressions in line C6.2, but a significant difference was not found between WT and the T2 seedlings of C6.2 (Figure S5). This shows that the low $\mathrm{Cd}$ accumulation in the OsABCG48-overexpressing seedlings was independent of a change in expressions of those four genes.

A

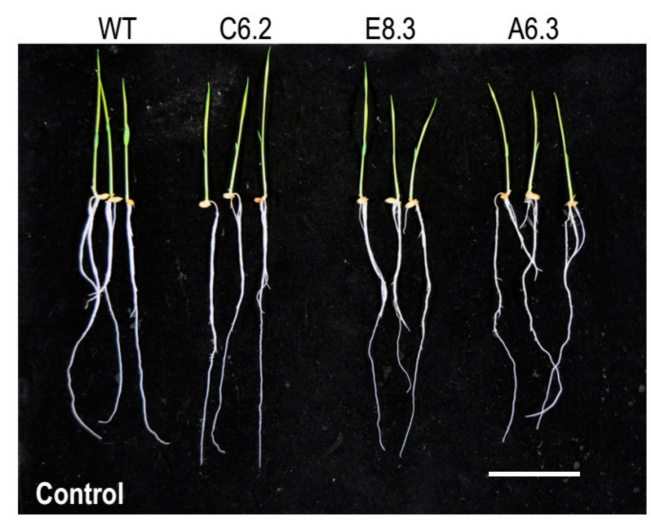

C

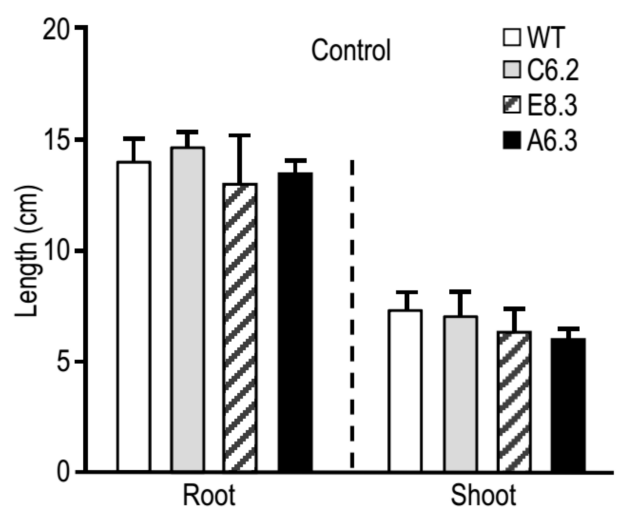

$\mathrm{E}$

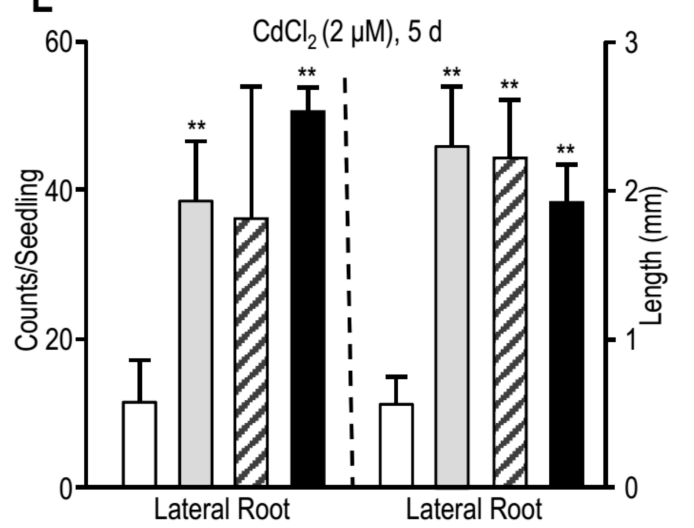

B

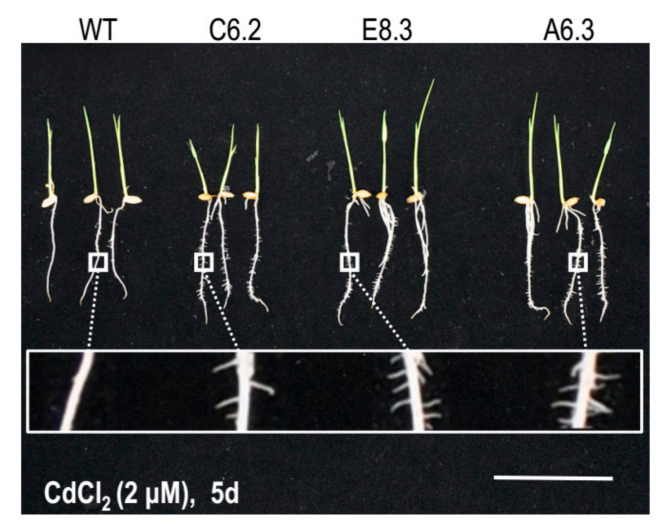

D
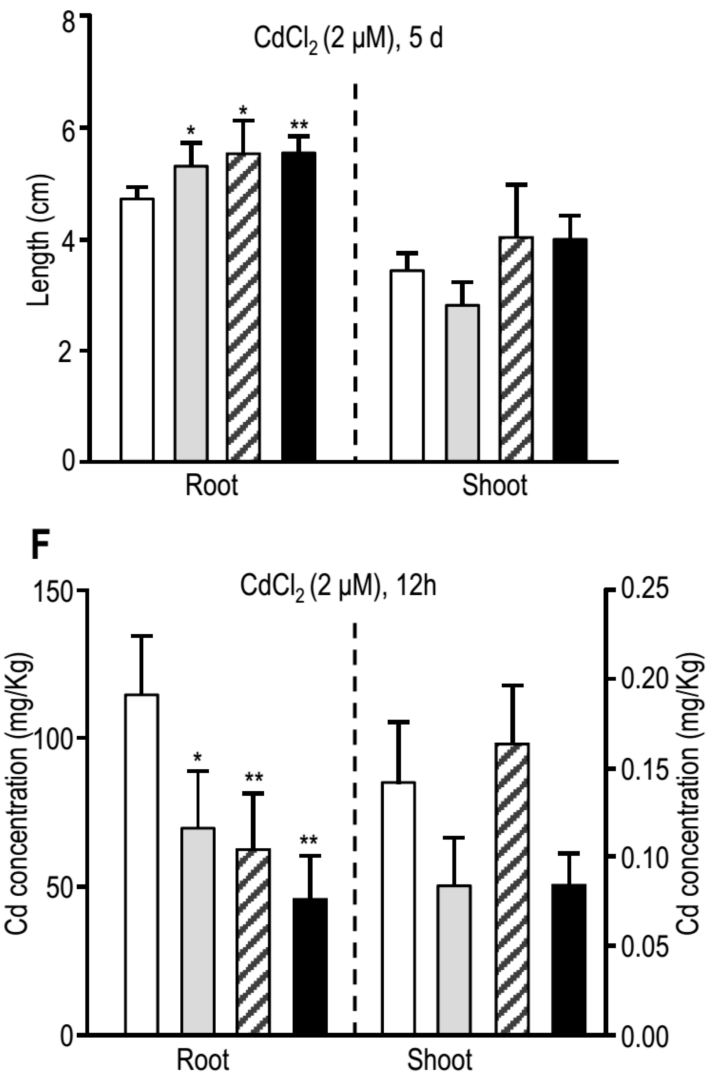

Figure 5. Expression of OsABCG48 confers tolerance to $\mathrm{Cd}$ and lowers $\mathrm{Cd}$ accumulation in $\mathrm{T} 2$ rice. Two-day-old $\mathrm{T} 2$ seedlings from $\mathrm{T} 1$ lines (C6.2, E8.3, A6.3) were grown in 1/2 Kimura B solution (pH 5.6) for 5 days (A) without Cd or (B) with $2 \mu \mathrm{M}$ $\mathrm{Cd}$, with insert showing 4-fold magnified view of lateral roots from primary roots $2 \mathrm{~cm}$ from root tip. (C,D) Root and shoot lengths recorded from (A) and (B), respectively. (E) Number and length of lateral roots derived from primary roots shown as the insert in (B). (F) Cd accumulation in 28-day-old T2 seedlings from T1 lines (C6.2, E8.3 and A6.3) treated with $2 \mu \mathrm{M}$ Cd for $12 \mathrm{~h}$. Data (bar and error bar) are shown as mean $\pm \mathrm{SD}(n=3$ for root length and Cd concentration, and 15 for lateral roots length); statistical analysis by unpaired Student's $t$-test compared to WT $\left.{ }^{*} p<0.05,{ }^{* *} p<0.01\right)$; scale bar $=5 \mathrm{~cm}$. 


\section{Discussion}

The RNA-seq analysis revealed 1420 DEGs caused by genotype and treatment, but due to limited resources to investigate the numerous candidates, we focused on those likely involved in metal ion transport. The testing of five candidate genes in the fission yeast narrowed the search to two genes, OsABCG48 and OsHIPP43, which were able to enhance $\mathrm{Cd}$ tolerance in $S$. pombe. For OsABCG48, this might not be surprising since it is an ortholog of OsABCG43 (Figure S2) that had previously been reported to enhance $\mathrm{Cd}$ tolerance in the budding yeast [35]. According to the transmembrane analysis by TMHMM Server v. 2.0 (http:/ / www.cbs.dtu.dk/services/TMHMM/ accessed on 30 September 2020), OsABCG48 is similar to most full-size G-type ABC transporters, consisting of two conserved transmembrane domains (Figure S2). As with other ABC transporters, it is likely to be involved in substrate translocation across the lipid bilayer [36]. There are also several other $A B C$ transporters that have been reported to be associated with $\mathrm{Cd}$ transport, such as AtABCC1, AtABCC2, AtABCC3, AtPDR8 and OsABCG36 [37-40].

Since OsABCG48 enhanced Cd tolerance in Arabidopsis and rice as well as reduced root $C d$ accumulation in rice seedlings, OsABCG48 overexpression appears to mimic the same phenotype observed with seedlings overexpressing OsO3L2 [22]. This suggests that OsO3L2 might be an upstream regulator of OsABCG48, and this possibility is strengthened by the fact that OsO3L2 overexpression upregulated OsABCG48 expression (Figure 2D), but not vice versa (Figure S5). According to phylogenetic analysis, OsABCG40 is also a closely related member in the same clade as OsABCG43 and OsABCG48 (Figure S2). However, the RNA-seq data did not identify OsABCG40 as a DEG, and thus we excluded it from this investigation. As for OsABCG43 that was identified in the RNA-seq assay, not only were we unable to confirm differential expression by qRT-PCR but we were also unable to amplify its full-length cDNA from rice seedlings, as all our PCR products lacked $\sim 500 \mathrm{bp}$ of the 5' end of its coding sequence. Hence, despite its homology with OsABCG48, we did not investigate its ability to confer $\mathrm{Cd}$ tolerance in heterologous hosts.

Given that OsABCG48 might function independently of previously identified transporters that can recognize $\mathrm{Cd}$ as a substrate (OsNramp5, OsHMA3 and OsLCT1) (Figure S5), OsABCG48 could be in a different $C d$ transport pathway. However, future studies are needed to determine whether OsABCG48 is indeed capable of transporting $\mathrm{Cd}$, and if so, whether low $\mathrm{Cd}$ accumulation is due to reduced $\mathrm{Cd}$ into, or higher $\mathrm{Cd}$ out of, plant roots. Moreover, even if we could ascertain that OsABCG48 is an important determinant, it does not rule out the possibility of other DEGs contributing to the OsO3L2-mediated low-Cd phenotype, or miRNAs not identified by our RNA-seq but which may also regulate Cd-responsive genes including the ABCG family member AtPDR8 [41].

\section{Conclusions}

RNA-seq led to discovering that OsABCG48 can enhance Cd tolerance in S. pombe, Arabidopsis and rice. Moreover, OsABCG48 overexpression in rice lowered root Cd accumulation that may be due to promoting lateral root development. From the view of biotechnology, this study adds a potential new tool to modify rice for reduced dietary intake of a nonessential but toxic metal. However, since the OsABCG48 overexpression lines tested thus far have multiple loci, practical engineering for a stable trait awaits further experiments on T3 and T4 homozygous seeds from single-locus (and single-copy) lines. It would also be interesting to speculate that since overexpression of OsABCG48 could reduce $\mathrm{Cd}$ accumulation, the down-regulation of OsABCG48 might be expected to increase $\mathrm{Cd}$ accumulation. If so, that could be useful for phytoremediation, like mutant cases of the CAX1 gene from Brassica rapa and OsABCG36 [40,42].

Supplementary Materials: The following are available online at http:/ /www.mdpi.com/xxx/s1. Figure S1: Verification of OsHIPP43-a, OsHIPP43-b, OsABCG48-a, OsABCG48-b and SALK_082843 in Arabidopsis. Figure S2. Phylogenetic analysis of G subfamily of ABC proteins from Arabidopsis and rice and transmembrane analysis of OsABCG48. Figure S3: OsABCG48 expression lines tested for Mn 
or $\mathrm{Cu}$ tolerance in Arabidopsis. Figure S4: Relative expression of OsABCG48 in rice organs/tissues. Figure S5: Expression of OsNRAMP5, OsHMA3, OsLCT1 and OsO3L2 in OsABCG48 overexpression line C6.2. Table S1: Primers sequences. Tables S2-S5: DEGs from WT $-\mathrm{Cd}$ vs. WT $+\mathrm{Cd}, 2 \mathrm{~B}-\mathrm{Cd}$ vs. $2 \mathrm{~B}+\mathrm{Cd}, 2 \mathrm{~B}-\mathrm{Cd}$ vs. $\mathrm{WT}-\mathrm{Cd}$ and $2 \mathrm{~B}+\mathrm{Cd}$ vs. $\mathrm{WT}+\mathrm{Cd}$, respectively. Table S6: Transformation of $O s A B C G 48$ in rice.

Author Contributions: Conceptualization, X.C., C.W. and D.W.O.; methodology, X.C., C.W., Y.J., M.W. and D.W.O.; formal analysis, X.C., C.W. and D.W.O.; writing-original draft preparation, X.C.; writing-review and editing, D.W.O., C.W.; supervision, C.W., D.W.O.; project administration, D.W.O.; funding acquisition, D.W.O. All authors have read and agreed to the published version of the manuscript.

Funding: This research was supported by the National Key R\&D Project (Grant No. 2016YFD0101904) from the Ministry of Science and Technology of China and the Key Research Program of Frontier Sciences CAS, China (Grant No. QYZDY-SSW-SMC010).

Institutional Review Board Statement: Not applicable.

Informed Consent Statement: Not applicable.

Data Availability Statement: Illumina reads of all samples are deposited in the Sequence Read Archive at the National Center for Biotechnology Information (http:/ / www.ncbi.nlm.nih.gov/sra under accession number PRJNA681035).

Conflicts of Interest: The authors declare no conflict of interest.

\section{References}

1. Zhang, S.; Hao, S.; Qiu, Z.; Wang, Y.; Zhao, Y.; Li, Y.; Gao, W.; Wu, Y.; Liu, C.; Xu, X.; et al. Cadmium disrupts the DNA damage response by destabilizing RNF168. Food Chem. Toxicol. 2019, 133, 110745. [CrossRef] [PubMed]

2. Reynders, H.; Van Campenhout, K.; Bervoets, L.; De Coen, W.M.; Blust, R. Dynamics of cadmium accumulation and effects in common carp (Cyprinus carpio) during simultaneous exposure to water and food (Tubifex tubifex). Environ. Toxicol. Chem. 2006, 25, 1558-1567. [CrossRef] [PubMed]

3. Assche, F.V.; Clijsters, H. Effects of metals on enzyme activity in plants. Plant Cell and Environ. 1990, 13, 195-206. [CrossRef]

4. Dietz, K.J.; Baier, M.; Krämer, U. Free radicals and reactive oxygen species as mediators of heavy metal toxicity in plants. In Heavy Metal Stress in Plants; Springer: Berlin/Heidelberg, Germany, 1999; pp. 73-97.

5. Hernández, L.E.; Cooke, D.T. Modification of the root plasma membrane lipid composition of cadmium-treated Pisum sativum. J. Exp. Bot. 1997, 48, 1375-1381. [CrossRef]

6. Järup, L.; Akesson, A. Current status of cadmium as an environmental health problem. Toxicol. Appl. Pharmacol. 2009, 238, 201-208. [CrossRef]

7. Järup, L.; Berglund, M.; Elinder, C.G.; Nordberg, G.; Vahter, M. Health effects of cadmium exposure-a review of the literature and a risk estimate. Scand. J. Work. Environ. Health 1998, 24 (Suppl. 1), 1-51.

8. Egan, S.K.; Bolger, P.M.; Carrington, C.D. Update of US FDA's Total Diet Study food list and diets. J. Expo. Sci. Environ. Epidemiol. 2007, 17, 573-582. [CrossRef]

9. Shimbo, S.; Zhang, Z.W.; Watanabe, T.; Nakatsuka, H.; Matsuda-Inoguchi, N.; Higashikawa, K.; Ikeda, M. Cadmium and lead contents in rice and other cereal products in Japan in 1998-2000. Sci. Total Environ. 2001, 281, 165-175. [CrossRef]

10. Jin, T.; Nordberg, M.; Frech, W.; Dumont, X.; Bernard, A.; Ye, T.T.; Kong, Q.; Wang, Z.; Li, P.; Lundström, N.G.; et al. Cadmium biomonitoring and renal dysfunction among a population environmentally exposed to cadmium from smelting in China (ChinaCad). Biometals 2002, 15, 397-410. [CrossRef] [PubMed]

11. Rivai, I.F.; Koyama, H.; Suzuki, S. Cadmium content in rice and its daily intake in various countries. Bull. Environ. Contam. Toxicol. 1990, 44, 910-916. [CrossRef]

12. Honda, R.; Swaddiwudhipong, W.; Nishijo, M.; Mahasakpan, P.; Teeyakasem, W.; Ruangyuttikarn, W.; Satarug, S.; Padungtod, C.; Nakagawa, H. Cadmium induced renal dysfunction among residents of rice farming area downstream from a zinc-mineralized belt in Thailand. Toxicol. Lett. 2010, 198, 26-32. [CrossRef]

13. Rizwan, M.; Ali, S.; Abbas, T.; Zia-Ur-Rehman, M.; Hannan, F.; Keller, C.; Al-Wabel, M.I.; Ok, Y.S. Cadmium minimization in wheat: A critical review. Ecotoxicol. Environ. Saf. 2016, 130, 43-53. [CrossRef] [PubMed]

14. Horiguchi, H.; Teranishi, H.; Niiya, K.; Aoshima, K.; Katoh, T.; Sakuragawa, N.; Kasuya, M. Hypoproduction of erythropoietin contributes to anemia in chronic cadmium intoxication: Clinical study on Itai-itai disease in Japan. Arch. Toxicol. 1994, 68, 632-636. [CrossRef]

15. Japan for Sustainability Home Page. Available online: https://www.japanfs.org/en/news/archives/-news_id032147.html (accessed on 14 July 2020).

16. Sasaki, A.; Yamaji, N.; Yokosho, K.; Ma, J.F. Nramp5 is a major transporter responsible for manganese and cadmium uptake in rice. Plant Cell 2012, 24, 2155-2167. [CrossRef] 
17. Ishikawa, S.; Ishimaru, Y.; Igura, M.; Kuramata, M.; Abe, T.; Senoura, T.; Hase, Y.; Arao, T.; Nishizawa, N.K.; Nakanishi, H. Ion-beam irradiation, gene identification, and marker-assisted breeding in the development of low-cadmium rice. Proc. Natl. Acad. Sci. USA 2012, 109, 19166-19171. [CrossRef]

18. Ueno, D.; Yamaji, N.; Kono, I.; Huang, C.F.; Ando, T.; Yano, M.; Ma, J.F. Gene limiting cadmium accumulation in rice. Proc. Natl. Acad. Sci. USA 2010, 107, 16500-16505. [CrossRef]

19. Uraguchi, S.; Kamiya, T.; Sakamoto, T.; Kasai, K.; Sato, Y.; Nagamura, Y.; Yoshida, A.; Kyozuka, J.; Ishikawa, S.; Fujiwara, T. Low-affinity cation transporter (OsLCT1) regulates cadmium transport into rice grains. Proc. Natl. Acad. Sci. USA 2011, 108, 20959-20964. [CrossRef] [PubMed]

20. Shimo, H.; Ishimaru, Y.; An, G.; Yamakawa, T.; Nakanishi, H.; Nishizawa, N.K. Low cadmium (LCD), a novel gene related to cadmium tolerance and accumulation in rice. J. Exp. Bot. 2011, 62, 5727-5734. [CrossRef] [PubMed]

21. Wang, C.; Guo, W.; Ye, S.; Wei, P.; Ow, D.W. Reduction of Cd in rice through expression of OXS3-like gene fragments. Mol. Plant 2016, 9, 301-304. [CrossRef]

22. Wang, C.; Guo, W.; Cai, X.; Li, R.; Ow, D.W. Engineering low-cadmium rice through stress-inducible expression of OXS3-family member genes. N. Biotechnol. 2019, 48, 29-34. [CrossRef] [PubMed]

23. Blanvillain, R.; Kim, J.H.; Wu, S.; Lima, A.; Ow, D.W. OXIDATIVE STRESS 3 is a chromatin-associated factor involved in tolerance to heavy metals and oxidative stress. Plant J. 2009, 57, 654-665. [CrossRef]

24. Liang, M.; Xiao, S.; Cai, J.; Ow, D.W. OXIDATIVE STRESS 3 regulates drought-induced flowering through APETALA 1. Biochem. Biophys. Res. Commun. 2019, 519, 585-590. [CrossRef]

25. Trapnell, C.; Williams, B.A.; Pertea, G.; Mortazavi, A.; Kwan, G.; van Baren, M.J.; Salzberg, S.L.; Wold, B.J.; Pachter, L. Transcript assembly and quantification by RNA-seq reveals unannotated transcripts and isoform switching during cell differentiation. Nat. Biotechnol. 2010, 28, 511-515. [CrossRef] [PubMed]

26. Benjamini, Y.; Hochberg, Y. Controlling the False discovery rate: A practical and powerful approach to multiple testing. J. R. Stat. Soc. B. 1995, 57, 289-300. [CrossRef]

27. Weghe, J.G.V.; Ow, D.W. A fission yeast gene for mitochondrial sulfide oxidation. J. Biol. Chem. 1999, $274,13250-13257$. [CrossRef] [PubMed]

28. Gietz, R.D.; Woods, R.A. Yeast transformation by the LiAc/SS Carrier DNA/PEG method. Methods Mol. Biol. 2006, 313, 107-120. [PubMed]

29. Zhang, X.R.; Henriques, R.; Lin, S.S.; Niu, Q.W.; Chua, N.H. Agrobacterium-mediated transformation of Arabidopsis thaliana using the floral dip method. Nat.Protoc. 2006, 1, 641-646. [CrossRef]

30. Hiei, Y.; Ohta, S.; Komari, T.; Kumashiro, T. Efficient transformation of rice (Oryza sativa L.) mediated by Agrobacterium and sequence analysis of the boundaries of the T-DNA. Plant J. 1994, 6, 271-282. [CrossRef]

31. Luo, J.S.; Huang, J.; Zeng, D.L.; Peng, J.S.; Zhang, G.B.; Ma, H.L.; Guan, Y.; Yi, H.Y.; Fu, Y.L.; Han, B.; et al. A defensin-like protein drives cadmium efflux and allocation in rice. Nat. Commun. 2018, 9, 645. [CrossRef]

32. Yan, H.; Xu, W.; Xie, J.; Gao, Y.; Wu, L.; Sun, L.; Feng, L.; Chen, X.; Zhang, T.; Dai, C.; et al. Variation of a major facilitator superfamily gene contributes to differential cadmium accumulation between rice subspecies. Nat. Commun. 2019, 10, 2562. [CrossRef]

33. Zhang, H.; Zhang, X.; Liu, J.; Niu, Y.; Chen, Y.; Hao, Y.; Zhao, J.; Sun, L.; Wang, H.; Xiao, J.; et al. Characterization of the Heavy-Metal-Associated Isoprenylated Plant Protein (HIPP) Gene Family from Triticeae Species. Int. J. Mol.Sci. 2020, 21, 6191. [CrossRef]

34. Robinson, N.J.; Winge, D.R. Copper Metallochaperones. Annu. Rev. Biochem. 2010, 79, 537-562. [CrossRef] [PubMed]

35. Oda, K.; Otani, M.; Uraguchi, S.; Akihiro, T.; Fujiwara, T. Rice ABCG43 is cd inducible and confers Cd tolerance on Yeast. Biosci. Biotechnol. Biochem. 2011, 75, 1211-1213. [CrossRef]

36. Kang, J.; Park, J.; Choi, H.; Burla, B.; Kretzschmar, T.; Lee, Y.; Martinoia, E. Plant ABC Transporters. Arab. Book 2011, 9 , e0153. [CrossRef] [PubMed]

37. Kim, D.Y.; Bovet, L.; Maeshima, M.; Martinoia, E.; Lee, Y. The ABC transporter AtPDR8 is a cadmium extrusion pump conferring heavy metal resistance. Plant J. 2007, 50, 207-218. [CrossRef] [PubMed]

38. Park, J.; Song, W.Y.; Ko, D.; Eom, Y.; Hansen, T.H.; Schiller, M.; Lee, T.G.; Martinoia, E.; Lee, Y. The phytochelatin transporters AtABCC1 and AtABCC2 mediate tolerance to cadmium and mercury. Plant J. 2012, 69, 278-288. [CrossRef]

39. Brunetti, P.; Zanella, L.; De Paolis, A.; Di Litta, D.; Cecchetti, V.; Falasca, G.; Barbieri, M.; Altamura, M.M.; Costantino, P.; Cardarelli, M. Cadmium-inducible expression of the ABC-type transporter AtABCC3 increases phytochelatin-mediated cadmium tolerance in Arabidopsis. J. Exp. Bot. 2015, 66, 3815-3829. [CrossRef] [PubMed]

40. Fu, S.; Lu, Y.; Zhang, X.; Yang, G.; Chao, D.; Wang, Z.; Shi, M.; Chen, J.; Chao, D.Y.; Li, R.; et al. The ABC transporter ABCG36 is required for cadmium tolerance in rice. J. Exp. Bot. 2019, 70, 5909-5918. [CrossRef]

41. Pegler, J.L.; Oultram, J.M.J.; Nguyen, D.Q.; Grof, C.P.L.; Eamens, A.L. MicroRNA-mediated responses to cadmium stress in Arabidopsis thaliana. Plants 2021, 10, 130. [CrossRef]

42. Navarro-León, E.; Ruiz, J.M.; Albacete, A.; Blasco, B. Tolerance to cadmium toxicity and phytoremediation potential of three Brassica rapa cax1a tilling mutants. Ecotoxicol. Environ. Saf. 2020, 189, 109961. [CrossRef] 